\title{
Bir Eğitim Araştırma Hastanesi Acil Servisine Başvuran Hastaların Analizi: Adli Vakalar
}

\author{
An Analysis of Patients Admitted to the Emergency Department of An Education \\ and Research Hospital: Forensic Cases
}

\author{
Ali GÜNDÜZ1', Sema KOÇAŞLI ${ }^{2}$
}

İletişim/ Correspondence: Ali GÜNDÜZ Adres/ Address: Atatürk Eğitim Araştırma Hastanesi, Acil Servis Bölümü, Ankara Tel: 03122912525 /32 70

E-mail: gunduz.a14@gmail.com

$\ddot{O} Z$

Amaç: Çalışma, bir eğitim araştırma hastanesinin acil servisine bir yll içinde başvuran adli vakaların genel bir profilini ortaya koymak amacıyla yapıldl.

Yöntem: Çalışmada, bir eğitim araştırma hastanesinin acil servisine bir yll içinde başvuran 145.250 hasta, geriye dönük incelendi. Adli vakaların kayıtları acil servise başvuru yapan diğer hasta kayıtlarının tutulduğu dosyada bulunmaktadır. Vakalar yass, cinsiyet, olay türü, olay türünün yaş ve cinsiyete bağlı dağgllmı yönlerinden tarandı. Veriler SPSS 16.0 paket programında değerlendirildi.

Bulgular: Çalı̧̧mada, başvuruların 5.844'ünün (\%4) adli vaka ve 139.406'sının (\%96) adli vaka dışındaki olgular olduğu saptandl. Acil servise yapılan adli vaka başvuruları içinde trafik kazaları \%37.6 ile ilk sırada yer aldl.

Sonuç: Çalı̧̧mada acil servise başvuran kazazedelerin adli vaka profilleri çıkarılmıştır. Bu profil doğrultusunda sağlık profesyonellerinin multidisipliner ekip yaklaşımı doğrultusunda adli vakalara yaklaşımı, bakım vermesi ve ilgili yasal süreçleri takip etmesi önem taşımaktadır.

Anahtar Kelimeler: Acil servis, adli vakalar, hemşirelik.

\section{ABSTRACT}

Aim: The aim of this study is to explore of the patients who admitted to the emergency department of a training and research hospital due to forensic cases in a year.

Method: In this study files of 145.250 patients who admitted to emergency department of a training and research hospital in a year were reviewed retrospectively. Cases were screened for age, gender, type of event. The data was collected from the registry book and evaluted by using 16.0 package program.

Results: We found that 5.844 (4\%) of the admissions were legislative cases and 139.406 (96\%) of them were non-legislative cases. The most common type of forensic case was traffic accidents with $37.6 \%$.

Conclusion: Forensic case profiles have been issued for victims who apply for emergency services. In line with this profile, it is important for health professionals to follow judicial approach, care and related legal processes in the direction of multidisciplinary team approach.

Keywords: Emergency service, forensic cases, nursing.

${ }^{I}$ Hemşire Atatürk Eğitim Araştırma Hastanesi, Ankara/ TURKEY, Yrd. Doç. Dr. Yıldırım Beyazıt Üniversitesi Sağllk Bilimleri Fakültesi, Ankaral TURKEY

Yazının gönderilme tarihi: 29.04.2016

Yazının basım için kabul tarihi: 22.06.2017

doi: 10.17672/fnhd.79640 


\section{GíRiş}

Acil servisler, evrensel bir sağlık problemi olarak tanımlanan suç ve şiddet olaylarında, mağdur veya faillerin sıç̧a başvurduğu birimlerdir. Dolayısıyla adli vakaların muayenesinin ve tedavisinin ilk gerçekleştiği yer de genellikle acil servislerdir. Her türlü ateşli silah, patlayıcı madde, kesici, kesici-batıcı (kesici-delici), batıcı (delici), kesici-ezici ve ezici alet ile olan yaralanmalar, trafik kazaları, düşmeler, darp olguları, iş kazaları, zehirlenmeler, yanıklar (alev, kızgın cisim, yakıcı-aşındırıcı madde vb.), elektrik ve yıldırım çarpmaları, cinsel saldırılar, mekanik asfiksiler, her türlü intihar girişimleri, işkence iddiaları, tüm cinayet, intihar, kaza orijinli olduğundan kuşkulanılan şüpheli ölümler, ani ve beklenmedik ölümler adli vaka olarak değerlendirilmektedir (Çevik ve Beşer 2012; Gürbüz, Sayg1 ve Cila 2004; Güven, Bütün, Beyaztaş, Eren ve Korkmaz 2009; Seviner ve ark. 2013; Sunay ve Faruk 2001).

Acil servislerde adli vakaların değerlendirilmesi, muayenesinin yapılmas1, delillerin toplanmas1, korunmas1, saklanması ve rapor edilmesi, temel olarak hekim ile birlikte adli hemşire tarafından yapılmaktadır (Bahar 2008). Ancak ülkemizde görev tanımı yapılmış, yasal olarak tanımlanmış adli hemşireler bulunmamaktadır. Bu nedenle acil servis hemşiresinin ilk görevi hastanın fiziksel ve ruhsal bakımını yapmak olsa da, adli kanıtların tespiti, toplanması ve saklanmasında da önemli görevleri vardır. Genellikle hemşireler vakayı ilk gören, konuşan ve laboratuvar örneklerini alan kişiler olduklarından adli kanıtları tanımak konusunda çok dikkatli olmalıdırlar. İster mağdur isterse fail olsun acil servise gelen tüm kişilerin tıbbi kayıtlarının doğru ve eksiksiz olarak yapılması, üzerindeki giysilerin uygun bir şekilde çıkarılıp saklanması, alkol, uyutucu/ uyuşturucu gibi maddelerin tespiti için örnek alınmas1 ve çeşitli suçlarda gerek mağdur ve gerekse failden uygun bir şekilde biyolojik delillerin toplanması sürecinde hemşirelerin önemi büyüktür. Ayrıca hemşireler, alınan örneklerin uygun bir şekilde tespiti, toplanması, saklanması, ilgili mercilere teslim edilmesi ve kaydedilmesini sağlarlar. Böylece hasta haklarının korunmasının yanı sıra yasal işlemlerin doğru uygulanmasında da yönlendirici rol oynarlar (Bahar 2008; Çevik ve Başer 2012; Çilingir ve Hintistan 2012; İlçe, Yıldız, Baysal, Özdoğan ve Taş 2010; Köroğlu 2013; Saral 2009)

Tüm bu işlemlerin doğru ve eksiksiz yapılmasının yanı sıra kısa sürede yapılması ve kanıtların incelenmek üzere hızla ilgili mercilere ulaştırılması da çok önemlidir. Çünkü kan, idrar, sperm gibi bazı kanıtlar zaman içerisinde adli kanıt olma özelliklerini yitirebilmektedirler. Bu nedenle kan, idrar, sperm gibi laboratuvar örnekleri uygun tüplere alınmalı, mide içeriği, kimyasal madde, boya vb. gibi sıvı kanıtlar uygun kapalı kaplara konulmalı, üzerleri etiketlenmeli ve en kısa sürede incelenmek üzere ilgili mercilere ulaştırılmalıdır. Zaman geçtikçe adli kanıt olma özelliğini kaybetme riski olan kanıtlar 48-72 saat içinde incelenmelidir (Çilingir ve Hintistan 2012; İlçe ve ark. 2010; Saral 2009).

Bu bağlamda sağlık kuruluşları özellikle eğitim araştırma hastaneleri, adli olguların başvurduğu ilk yetkili mercilerden biri olması nedeniyle önemli bir görev üstlenmekte; acil servislerde çalışan hemşirelerin de adli vakalara yaklaşım konusunda dikkatli olması önem taşımaktadır (Bahar 2008; Seviner ve ark. 2013; Şentürk ve Büyükaslan 2013).

Bu çalışma, Bir Eğitim Araştırma Hastanesi'nin Acil Servisi'ne 2013 yılı içinde başvuran adli vakaların yaş, cinsiyet gibi demografik özellikleri ile olay türü, dağılımı ve oranının belirlenmesi, adli olgu profilinin ortaya çıkarılması amacıyla yapıldı.

\section{YÖNTEM}

\section{Araştırmanın Tipi}

$\mathrm{Bu}$ araştırma retrospektif bir çalışma olarak planlandı ve uyguland1.

\section{Araştırmanın Evreni ve Örneklemi}

$\mathrm{Bu}$ araştırmanın evrenini bir eğitim araştırma hastanesinin acil servisine 01.01.2013-31.12.2013 tarihleri arasında başvuran 145.250 hasta kaydı; bunlardan 
vaka türüne göre adli vaka olarak kayit edilen 5.844 hasta kaydı örneklemi oluşturdu.

\section{Veri Toplama Araçları ve Verilerin Toplanmasi}

$\mathrm{Bu}$ araştırmada bir eğitim araştırma hastanesinin acil servisine 01.01.2013-31.12.2013 tarihleri arasinda başvuran 145.250 hasta, geriye dönük olarak vaka türüne göre incelenmiştir. Bu başvurulardan 5.844'ü adli vaka olarak kayıt edilmiştir.

Araştırma retrospektif - geriye dönük hasta kayıtlarının incelenmesi amacıyla yapıldığ 1 için veri toplama aracı olarak acil servise başvuru yapan her tür hastanın kayıt altına alınan verileri kullanıldı. Adli vakaların kayitları da acil servise başvuru yapan diğer hasta kayitlarının tutulduğu "acil servis kayıt defterlerinde" bulunmaktaydı ve verilere bu kayıtlardan ulaşıldı. $\mathrm{Bu}$ kayıtlardaki vakalar yaş, cinsiyet, olay türü, olay türünün yaş ve cinsiyete bağlı dağılımı yönlerinden tarandi; SPSS programına kayıt edildi.

\section{Araştırmanın Etik Yönü}

Çalışmanın yapılabilmesi için Atatürk Eğitim Araştırma Hastanesi Başhekimliği'nden yazılı izin alındı.

\section{Verilerin Değerlendirilmesi}

Araştırma sonucunda elde edilen veriler, Statistical Package for the Social Sciences (SPSS) for Windows
16.0 paket programında yüzdelik, ki-kare ile değerlendirildi.

\section{Araştırmanın Sınırlııkları}

Geriye dönük dosya kayıtları incelenerek ulaşılması planlanan verilerde, zorlukların ve bazı verilere ait detaylı bilgilerin kayıtlarda olmaması çalışmanın kısıtlayıcı yönleridir. Benzer konuda ileriye dönük olarak planlanan çalışmalar ile acil servislerde düzenli kayıt tutulması, adli vakaların tanımlarının iyi yapılması ve sağlık profesyonellerinin adli vakalara yaklaşımının etkinleştirilmesine olumlu katkıları olacağı düşünülmektedir.

\section{BULGULAR}

Acil servisler başta olmak üzere sağlık kuruluşlarına gelen ya da getirilen mağdurların önemli bir bölümünü kaza, şiddet, intihar gibi adli nedenlere bağlı olgular oluşturduğundan sağlık personeli adli olgularla sık karşılaşmaktadır. Bu durum sağlık çalışanlarının adli kanıtları tespit etme, toplama, muhafaza etme ve raporlama konularındaki önemini de arttırmaktadir.

Bir eğitim araştırma hastanesinin acil servisine 2013 y1lında müracaat eden hasta sayısının 145.250, bunların 5.844' ünün (\%4) adli vaka olduğu (Şekil 1); bu vakaların, \%66.3'ünün (n: 3874) erkeklerden, \%33.7'sinin (n: 1970) kadınlardan oluştuğu saptanmıştır (Şekil 2).

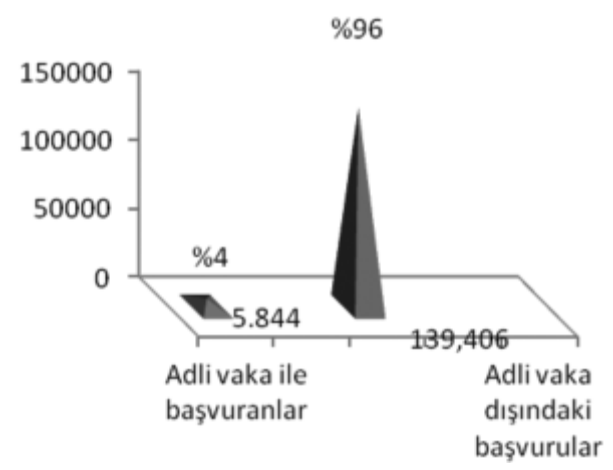

Şekil 1. Acil Servise Adli Vaka ve Adli Vaka Dışındaki Başvuruların Dağılımı (N: 145.250) 


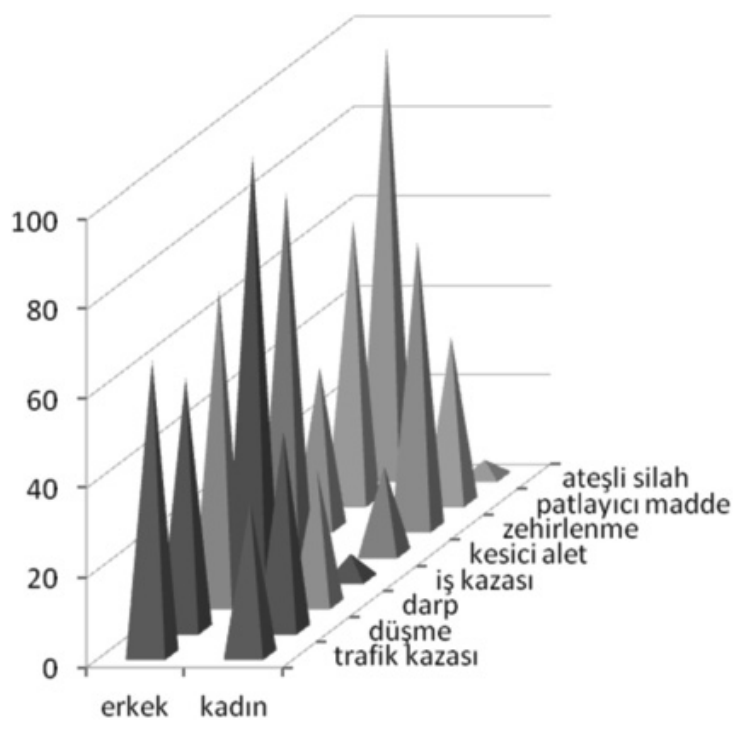

- trafik kazası

घ düşme

- darp

" iş kazası

nesicialet

nzehirlenme

w patlayıcı madde

ateşli silah

Şekil 3.Adli Vakaların Cinsiyet ile Adli Vaka Türü Dağılımı (n=5.844)

Cinsiyet ile adli vaka türü dağılımlarında \%37.6 (n:2198) ile ilk sirada yer alan trafik kazalarını \%65.7'sini (n:1443) erkeklerin, \%34.3'ünü (n:755) kadınların oluşturduğu saptandı. Düşme/yüksekten düşme vakaları $\% 28.5$ oranı ile ikinci sırayı almakta, bunların \%56's1 (n: 932) erkekle- ri, \%44’ü (n: 632) kadınlanı kapsamaktadır. Üçüncü sırada $\% 11.1$ ile (n: 650) darp ile müracaat eden vakalar olup çoğunluğunu (\%70 n: 455) erkekler oluşturmaktadır. İş kazaları \%9.4 (n: 550) oranında en fazla (\%94.4 n: 519) erkekler arasında görülmektedir (Şekil 3).

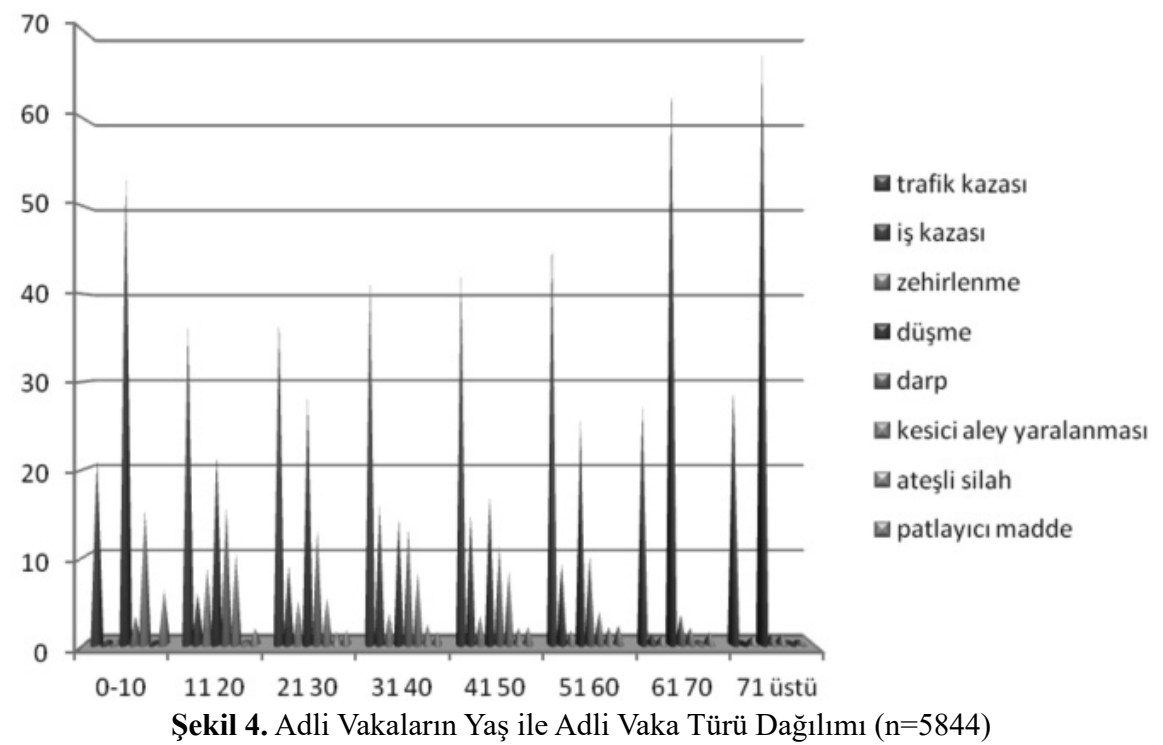


Acil servise başvuran adli vakaların yaş ile adli vaka türü dağılımı incelendiğinde, birinci sırayı alan trafik kazalarında yoğunluğun \%31.8 (n:700) ile 21-30 yaş grubunda, darp ile müracaat eden vakaların \%37.7'sinin (n:245) 21-30 yaş grubunda; iş kazası ile başvuran vakaların çoğunluğunun (\%32 n: 176) 31-40 yaş grubunda olduğu tespit edilmiştir. Kesici- delici alet yaralanması ile müracaat eden adli vakaların \%25.7 (n:98) ile 21-30 yaş grubu olduğu, ateşli silah yaralanmaları sonucu müracaatların \%65.4'ünün (n:51) 2140 yaş grubunda toplandığı saptandi. Adli vaka olarak başvuran 71 yaş ve üstü kazazedelerin \%16.4' sinin (n: 262), \%10.6 (n: 177) oranında düşme ile başvuru yaptığ 1 belirlendi.

Adli vakaların aylara göre dağ 1 lımında, trafik kazalarına yoğunluklu (\%10.9 n: 239) olarak \%10.4 (n: 229) oranı ile Eylül ayında rastlandığı saptandı. Zehirlenmelerin aylara göre dağılımında Aralık- Ocak aylarında (\%29.1 n: 65) yoğunlaştığ1; düşme/yüksekten düşmelerin Kasım ve Şubat aylarında arttığı (\%32.5 n: 540) görülmektedir. Mayıs ayında darp vakaları $\% 15.5$ (n: 101), Ocak ayında ise \%17.9 (n: 14) ateşli silah yaralanmaları, diğer aylara göre ön plana çıkmaktadır.

\section{TARTIŞMA}

Çalışmada Ankara Atatürk Eğitim Araştırma Hastanesi Acil Servisine 1.1.2013-31.12.2013 tarihleri arasinda başvuran adli olguların \%66.3'ünü (n:3874) erkek, \%33.7'sini (n:1970) kadın oluşturmuştur ve yapılan diğer çalışmalarda elde edilen sonuçlarla uyumlu olduğu saptanmıştır (Emet, Beyhun, Özüçelik ve Fidan 2006; Gürbüz ve ark. 2004; Seviner ve ark. 2005; Türkmen, Akgöz, Çoltu ve Ergin 2005). Bu durumun, toplumumuzda erkek birey nüfusunun fazla olması, erkek bireylerin ev dışı işlerde aktif olarak daha fazla çalışmaları ve kazalara daha açık olmalarına bağlanmıştır.

Acil servise başvuran adli vakalar içinde ilk sırayı \%37.6 (n:2198) ile trafik kazalar1, \%28.5 (n:1664) ile düşmeler/yüksekten düşmeler almıştır. Daha sonra s1rasıyla \%11.1 (n:650) darp, \%9.4 (n:550) iş kazaları gelmektedir. Acil servise başvuran adli vakaların incelendiği çalışmalarda da trafik kaza olgularının ilk s1rayı alması çalışmamızı desteklemektedir. Bu durum, artan araç sayısına paralel olarak yoğun iş temposu ile çalışan insanların zamanlarını trafikte geçirmek istememeleri ve bu nedenle kuralları ihlal ettikleri düşünülebilinir (Emet ve ark 2006; Gürbüz ve ark 2004; Güven ve ark. 2009). Düşme/yüksekten düşme olgularının diğer çalışmalardan farklı oranda çıkmasını geriatrik (65 yaş üstü) düşmeler, çocuk düşmeleri ve şüpheli düşmelerin adli olgu olarak kabulünün yapılmasına bağlanmıştır.

Acil servislere başvuran düşme/yüksekten düşmelerin yaşlanmayla beraber arttığı sık görülmektedir. Meriç ve Oflaz'ın yapmış olduğu çalışmada yer alan 22 yaş1 hastanın \%12.2'sinin en az bir kere düştüğü ve hep

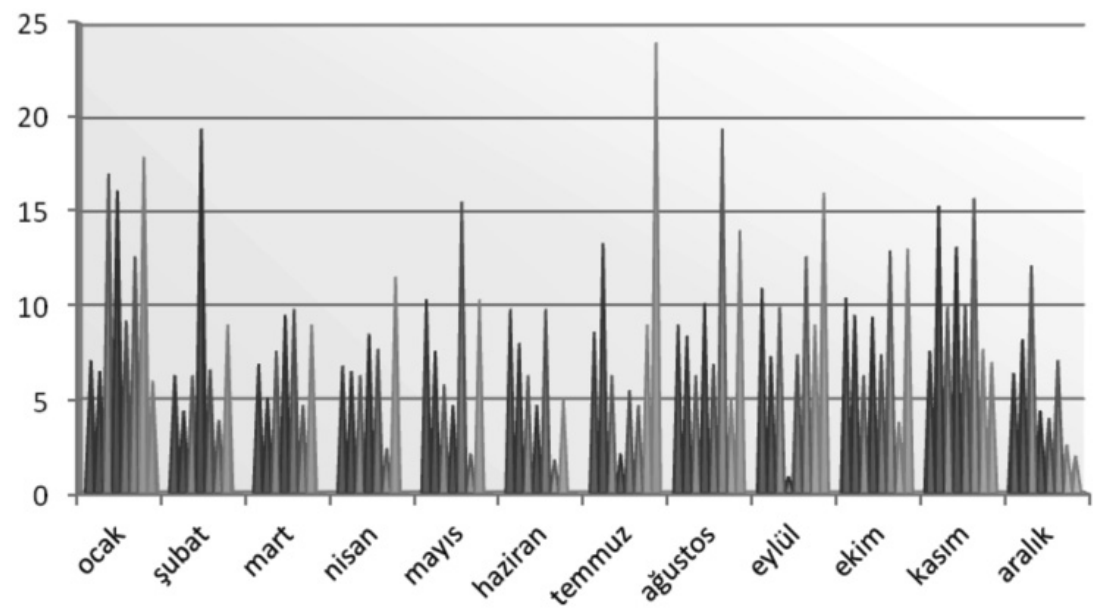

Şekil 5. Adli Vakaların Aylara Göre Dağılımı (n: 5844)

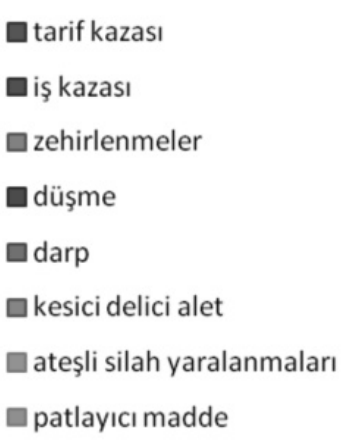

a patlayıcı madde 
düşme korkusunu yaşadıkları görülmüştür (Meriç ve Oflaz 2007). Huzurevinde yürütülen bir çalışmada bir yıllık düşme sıklığı \%33.9 olarak bulunmuştur (Kırım11 2002). Çalışmamızda ise 71 yaş ve üstü hastaların \%16.4'ünün (n: 262), \%10.6 (n: 177) oranında düşme vakası ile geldiği saptanmıştır. Bu oranların yaşlanmaya bağlı sorunlara; görme keskinliğinde azalma, karanlığa uyumda azalma, göz kamaşması, reaksiyon süresinde yavaşlama, postürde bozulma veya uygunsuz çevre koşullarına bağlı olarak geliştiğini söyleyebiliriz. Bu veriler doğrultusunda dikkatimizi 71 yaş ve üstü üzerinde yoğunlaştırmamızın nedeni bu hastaların kendilerini ifade etmekte yetersiz kaldıkları veya yakınlarının koruma amaçlı ifadelere bulunmaları, bu başvuruların yaşlı istismarı olabileceği şüphesi doğrultusunda adli vaka olgusu olarak kabul edilmesidir.

Çalışmamızda iş kazaları ile başvuran olguların oranı \%9.4 (n:550) olarak bulunmuştur. Diğer benzer yap1lan çalışmalarda bu oran daha düşük tespit edilmiştir. $\mathrm{Bu}$ farklılı̆ğn hastanenin bulunduğu konumun sanayi bölgesine yakın olması, üçüncü basamak acil olması; iş kazalarının 21-40 yaş aralığında yoğunlaşması ise bu yaş gruplarında mesleki üretkenliğin fazla olması ve iş hayatında daha fazla rol almalarından kaynaklanabileceği düşünülmüştür (Güven ve ark. 2009; Seviner ve ark. 2013; Türkmen ve ark. 2005).

Çalışmamızda zehirlenme olguları ilk sıralara giremese de görülme oranı önemlidir. Zehirlenme olgular1nın kadınlarda (\%64.1) erkeklere (\%35.9) göre daha fazla olduğu, daha çok genç yaş grubunu kapsadığı ve yoğunluk olarak Ocak ve Aralık (\%29.1) aylarında görüldüğü saptandı. Kıyan ve ark. (2009)'nın zehirlenme şikayeti ile gelen hastaları inceledikleri çalışmada kadınların çoğunlukta (\%80) ve en sık başvuru mevsiminin Mayıs-Haziran aylarında yapıldığını tespit etmişlerdir. Yılmaz ve ark. (2006)'nın, Yağan ve ark. (2009)'nın, Uludağ ve ark. (2015)'nın, Erdoğan ve ark. (2013)'nın da yaptıkları çalışmalarda zehirlenmelerin çoğunlukla kadınlarda ve kaynağın ilaç zehirlenmeleri olduğu belirtilmiştir. Literatür ile uyumluluk gösteren çalışmamızdaki bu sonuçların, toplumumuzda bazı kısıtlayıcı sosyal ve kültürel faktörlerin aşırı stres yaratmasının yanı sıra altta yatan kişilik ve psikiyatrik rahatsızlıkların özellikle genç kadınların üzerinde sosyal baskı oluşturması ve bu grupta intihar girişimi amacıyla zehirlenmeleri arttırıyor olabileceği düşünülmektedir (Erdoğan, Uğuz ve Kaymak 2013; Kiyan ve ark. 2009; Uludağ ve ark. 2015).

\section{SONUÇ VE ÖNERÍLER}

Hasta sirkülasyonun hızlı, iş yükünün fazla olduğu acil servislerde adli vakaların azımsanmayacak oranda bulunması, acil serviste çalışan sağlık profesyonellerinin adli vakayı fark edebilmesi ve doğru, eksiksiz kayıt tutması açısından oldukça önemlidir. Çalışmada acil servise başvuran kazazedelerin adli vaka kayıtları incelenmiş ve bir profil çıkarılmıştır. Bu profil doğrultusunda sağlık profesyonellerinin multidisipliner ekip yaklaşımı doğrultusunda adli vakalara yaklaşımı, bakım vermesi ve ilgili yasal süreçleri takip etmesi önem taşımaktadır.

\section{KAYNAKLAR}

Bahar, M. T. (2008). Acil servislerde çalışan hemşireler tarafindan adli vakaların tanılanması. Yüksek Lisans Tezi, Marmara Üniversitesi Sağlık Bilimleri Enstitüsü, Istanbul.

Çevik, S. A., Başer, M. (2012). Adli hemşirelik ve çalışma alanları. Sağllk Bilimleri Derg. (Journal of Health Sciences), 21(2): 143-152.

Çilingir, D., Hintistan, S. (2012). Adli hemşireliğin kapsamı ve yasal boyutu. Hemşirelikte Eğitim ve Araştırma Derg., 9(1): 10-15.

Emet, M,. Beyhun, N. E., Özüçelik, D. N., Fidan, V. (2006). Bir devlet hastanesi acil servisinde trafik kazası vakaları. Türkiye Acil Tip Derg., 6(4): 149-153.

Erdoğan, M. N., Uğuz, M., Kaymak, S. (2013). Zile Devlet Hastanesi acil servisine başvuran intoksikasyon hastalarının değerlendirilmesi. Global Media Journal., 24: 113-116.

Gürbüz, N., Saygı. Ş., Cila, E. (2004). Gazi Üniversitesi Tıp Fakültesi Acil Anabilim Dalı erişkin acil servise başvuran adli vakaların analizi. Gazi Medical Journal., 15(4): 139-144.

Güven, F. M., Bütün, C., Beyaztaş, F. Y., Eren, Ş. H., Korkmaz, İ. (2009). Cumhuriyet Üniversitesi Tip Fakültesi Hastanesi'ne başvuran adli olguların değerlendirilmesi. A.D.Ü. Tlp Fakültesi Derg., 10(3): 23-28.

İlçe, A., Yıldız, D., Baysal, G., Özdoğan, F., Taş, F. (2010). Acil servislerde çalışan sağlık bakım personelinin adli olgularda delillerin korunması ve saklanmasına yönelik bilgi ve uygulamalarının incelenmesi. Ulus Travma Acil Cerrahi Derg., 16(6): 546-551. 
Kırımlı, E. (2002). Huzurevinde kalan yaşlılarda düşme sıklığı ve buna etki eden nedenler. Tipta Uzmanlık Tezi, Marmara Üniversitesi Tıp Fakültesi Aile Hekimliği Anabilim Dalı, İstanbul.

Kıyan, S. ve ark. (2009). Akut zehirlenme hastalarının iki yıllık değerlendirilmesi. Türkiye Acil Tip Derg., 9(1): 24-30.

Köroğlu, H. (2013). Acil hemşirelerinin adli vakalarda delil koruma yaklaşımları. Yüksek Lisans Tezi, Acıbadem Üniversitesi Sağlık Bilimleri Enstitüsü, İstanbul.

Meriç, M., Oflaz, F. (2007). Yaşıı bireylerin düşme yaşantısı ile algıları ve günlük yaşamlarına etkisi üzerine niteliksel bir çalışma. Turkish Journal of Geriatrics, 10(1): 19-23.

Saral, S. (2009). TSK hastaneleri acil servis hemşirelerinin adli olgulara ilişkin yaklaşımları. Yüksek Lisans Tezi, Marmara Üniversitesi Sağlık Bilimleri Enstitüsü, İstanbul.

Seviner, M. ve ark. (2013). Acil Tıp Kliniği'ne başvuran adli vakaların geriye dönük analizi. Çukurova Tip Fakültesi Derg., 38(2): 250-260.
Sunay, Y. M., Faruk, O. I. (2003). Süleyman Demirel Üniversitesi Tıp Fakültesi acil servisine 1999-2001 yılları arasında müracaat eden adli olguların değerlendirilmesi. Adli Tip Derg., 17(1): 47-53.

Şentürk, S. Büyükaslan, B. (2013). Hemşirelik son sınıf öğrencilerinin adli hemşirelik konusundaki bilgi ve görüşlerinin belirlenmesi: Bozok Tip Derg., 3(3): 19-26.

Türkmen, N., Akgöz, S., Çoltu, A., Ergin, N. (2005). Uludağ Üniversitesi Tıp Fakültesi acil servisine başvuran adli olguların değerlendirilmesi. Uludağ Üniversitesi Tip Fakültesi Derg., 31(1): 25-29.

Uludağ, Ö. ve ark. (2015). Adıyaman ilinde zehirlenme hastalarının özellikleri. Dicle Tip Derg., 42(3): 284-288.

Yağan, O. ve ark. (2009). The retrospective analysis of the acute poisoning cases applying to the emergency unit in one year. Şişli Etfal Hastanesi Tip Bulteni., 43(2): 60-64.

Yllmaz, A. ve ark. (2006). Retrospective analyse of acute poisoning in emergency department. Cumhuriyet U. Tip Derg., 28: 216. 